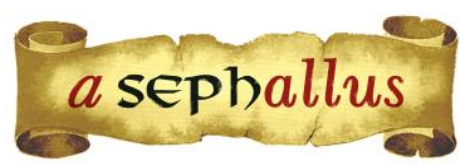

Revista aSEPHallus de Orientação Lacaniana

Núcleo Sephora de Pesquisa sobre o Moderno e o Contemporâneo

ISSN 1809 - 709 X

\title{
Entrevista com o psicanalista Antônio Teixeira
}

\section{Antônio Teixeira}

Orcid: 0000-0003-3867-2681.

Doutor pelo Département de Psychanalyse de Paris VIII ; Professor Titular do Programa de Pós-graduação em Psicologia na Universidade Federal de Minas Gerais / UFMG; Psicanalista, Membro da Escola Brasileira de Psicanálise / EBP; Membro da Associação Mundial de Psicanálise / AMP.

E-mail: amrteixeira@uol.com.br

Entrevista realizada em 27/09/2020 por:

Tania Coelho dos Santos Orcid: 0000-0002-5360-7864 Pós-doutorado no Departamento de Psicanálise de Paris VIII (Paris, França) Professor Associado, nível IV no Programa de Pós-graduação em Teoria Psicanalítica/UFRJ (Rio de Janeiro, Brasil) Pesquisadora Bolsista de Produtividade Científica do CNPQ nível $1 \mathrm{C}$ Presidente do Instituto Sephora de Ensino e Pesquisa de Orientação Lacaniana/ ISEPOL (Rio de Janeiro, Brasil) Psicanalista Membro da École de La Cause Freudienne, da Escola Brasileira de Psicanálise e da Associação Mundial de Psicanálise Membro da Associação Universitária de Pesquisa em Psicopatologia Fundamental (Rio de Janeiro, Brasil)

E-mail: taniacs@openlink.com.br

Rachel Amin

Orcid: 0000-0003-0074-9444

Psicanalista

Maîtrise em Psicopatologia em Paris V. Sorbonne Especialista em Teoria Psicanalítica pela UNESA/RJ Membro da Escola Brasileira de Psicanálise do Campo Freudiano Membro da Associação Mundial de Psicanálise.

Membro do Instituto Sephora de Pesquisa de Orientação Lacaniana -ISEPOL E-mail: rachelamin@uol.com.br

Jaqueline Ferreira Orcid: 0000-0001-7447-6034

Graduação e bacharel em psicologia (1988) pela Universidade FUMEC, especialização em psicologia do trabalho (2004) pela Universidade Federal de Minas Gerais (UFMG), mestrado em teoria psicanalítica (2011) e doutorado em teoria psicanalítica (2017) pela Universidade Federal do Rio de Janeiro (UFRJ). Formação e experiência como psicóloga colaboradora em recrutamento e seleção do Banco do Brasil e PREVI Caixa de Previdência dos Funcionários do Banco do Brasil, e educadora corporativa da Universidade Corporativa Banco do Brasil. Formação e experiência em psicologia organizacional, atuando nos seguintes processos de gestão de pessoas: recrutamento e seleção, orientação profissional e planejamento de carreira, gestão de desempenho por competências, mentoria, treinamento e desenvolvimento. Formação e experiência em atendimento clínico psicanálise Associada do Instituto Sephora de Pesquisa e Orientação Lacaniana - ISEPOL E-mail: jaquesil@uol.com.br 


\section{Entrevista com o psicanalista Antônio Teixeira}

Tania Coelho dos Santos \& Rachel Amin \& Jaqueline Ferreira

Endereçamos ao colega Antônio Teixeira, em nome de todo o Corpo Editorial de aSEPHallus Revista de Orientação Lacaniana, o pedido de que ele compartilhasse conosco suas reflexões acerca do impacto da pandemia do novo coronavírus na biopolítica no Brasil e no mundo. Antonio é conhecido pelo hábito de comentar as diferentes modalidades do mal-estar na cultura. Seu livro intitulado $A$ soberania do inútil ${ }^{\mathbf{1}}$ reúne artigos que abordam diversos ângulos do problema. Preparamos algumas perguntas, em particular, a respeito da biopolítica. É possível comparar os efeitos de uma tragédia de proporções gigantescas como essa pandemia que vivemos e o episódio de 11 de setembro? Muitas pessoas sentiram-se revivendo alguma coisa dessa ordem, especialmente, pelos efeitos que vão reverberar no comportamento dos povos e dos governos. Tania Coelho dos Santos deu início à entrevista perguntando:

Tania Coelho dos Santos: A pandemia desencadeou um combate entre os defensores do valor absoluto vida versus os defensores do valor da estabilidade econômica. Para os primeiros, não há tratamento para a Covid-19, só prevenção. Para os outros, estratégias de tratamento precoce (hidroxicloroquina, ivermectina, azitromicina) poderiam reduzir o impacto da doença e minimizar os efeitos econômicos. Esse combate colocou de um lado epidemiologistas descrentes do tratamento precoce e lutando em nome da ciência pura a favor do isolamento. De outro, médicos assistentes à serviço de estratégias clínicas baseadas no uso criterioso da medicação tradicional para quadros semelhantes de infecção respiratória. Esse combate revela uma politização da epidemia ou foi somente consequência de desconhecimento médico acerca da doença?

Antônio Teixeira: Agradeço imensamente a Tania Coelho, a Rachel Amin e a Jacqueline Ferreira a confiança pelo convite a reagir a essas questões, embora talvez não esteja à altura das expectativas de vocês para comentar de maneira satisfatória a natureza de uma situação que me escapa por diversas razões. Em primeiro lugar, porque embora venha de uma formação médica, há muito tempo não tenho dirigido minha atenção ao campo da infectologia e da epidemiologia de doenças infecciosas. Em segundo, por se tratar de um problema essencialmente contemporâneo, no sentido de algo para o qual as categorias pretéritas das quais normalmente nos servimos para comentar uma situação regrada perdem sua eficácia. Me vejo, nesse sentido, diante da obscuridade produzida pela fratura de uma situação que rompe com minhas disposições usuais de compreensão e assim me obrigam, como diz poeticamente Agamben ${ }^{2}$, a escrever mergulhando a pena nas trevas do presente para perceber não as luzes, mas o seu lado escuro. Parece-me, nesse sentido, que a ideia proposta nessa primeira pergunta de se falar de um combate de defensores da vida versus defensores da estabilidade econômica, 
talvez derive da necessidade de nos servirmos de esquemas já habilitados pelo nosso pensamento, e que podem nos dar a falsa sensação de dispor de uma iluminação para esclarecer a natureza do que estamos enfrentando. Mas eu penso, de minha parte, que não existe defesa possível da estabilidade econômica que não se apoie no valor axiomático, indiscutível, da preservação da vida, valendo enfatizar que quando falo aqui de preservação da vida, penso que está em questão, para além da preservação da existência biológica dos indivíduos, a preservação da vida como preservação de nossa capacidade vital de recusar tudo aquilo que venha negar o direito de existir em nome da sobrevivência de uma abstração discursiva, seja ela econômica ou sócio-política. É enganoso nesse sentido opor aqueles que dizem que só há prevenção aos que propõem estratégias de tratamento precoce, pelo simples fato, atestado por todos os estudos sérios disponíveis, de que não há tratamento precoce à infecção pela Covid 19; somente dispomos, nesse momento, de precários e custosos meios de prevenção. $O$ que existe é uma oposição entre aqueles que reconhecem uma situação de urgência vital e aqueles que tentam construir, mediante notificações absolutamente falsas acerca de uma suposta eficácia dos meios de tratamento precoce, um semblante que justifique a negligência desse direito axiomático de existir em nome de uma regulação discursiva determinada por interesses particulares. Nesse sentido, vale dizer que a dimensão escura da fratura de nosso presente se constitui a partir do próprio obscurantismo atual possibilitado pela divulgação, nas redes sociais, de informações desprovidas de senso crítico, em nome de posições ideológicas duvidosas.

TCS: O que você pensa das políticas de isolamento social? Elas podem induzir uma espécie de paranoia generalizada, medo, pânico e fobia social permanentes?

Existe, no meu entender, em relação à interpretação que atualmente se faz das políticas de isolamento social, um outro erro que resulta da transposição acrítica de categorias de uma situação para outra, como se um determinado termo tivesse o mesmo valor semântico em contextos distintos. Esse me parece ser um erro no qual incorrem até mentalidades esclarecidas, como foi o caso de Giorgio Agamben ${ }^{3}$, acima citado, que se insurgiu contra o perigo da consolidação de um Estado de exceção provocado por essas medidas de isolamento. Concordo com o que diz o filósofo português Boaventura de Souza Santos, quando ele afirma que Agamben não soube considerar, diante da própria excepcionalidade dessa exceção, a necessidade de distinguir, na fratura do presente, a crucial diferença entre Estado de exceção democrático e Estado de exceção antidemocrático. Uma democracia deve saber lidar com estados de exceção, sem deles se servir para gerar um regime autoritário. Eu creio, nesse sentido, que o próprio uso do termo isolamento talvez devesse ser revisto, em razão do peso semântico opressivo que essa palavra traz de outros contextos, o qual pode de fato induzir o que você chama de paranoia generalizada ou fobia social permanente. Pois se existe, até o 
momento, a necessidade de evitar aglomerações para preservar esse fundamento inquestionável que é o direito de existir, sejam quais forem as interpretações, muitas vezes enganosas, que se façam desse direito em termos de biopolítica e segurança social, é preciso encontrar meios de permitir que essas medidas sejam subjetiváveis, tratando-as em termos de cuidado e acolhimento, e mostrando que existem momentos em que a distância nos aproxima ao fazer cintilar o direito à vida como aquilo que nos reúne para além dos interesses particulares.

TCS: Você acredita que o "novo normal" com os imperativos de distância física, uso de máscaras, higienização frequente das mãos, desinfecção de roupas e objetos de uso pessoal, evitação de lugares públicos e aglomerações será capaz de modificar permanentemente as relações sociais, criando novas formas obsessivas compulsivas de mal-estar?

A bem dizer, o novo normal que realmente me preocupa não é esse que se traduz nos imperativos de distanciamento e na imposição de medidas de precaução. Tudo leva a crer que com a chegada da vacina, com a dissipação progressiva do risco de contágio pandêmico, alternada com ondas cada vez menores de recrudescimento, coisa que deve se afirmar no máximo até o fim do primeiro semestre do ano que vem, a exigência dessas medidas deve se abrandar, ainda que reste um temor preventivo que julgo aliás benéfico, se considerarmos que há décadas já deveríamos estar de sobreaviso sobre o risco de aparecimento desse tipo de fenômeno. Já se sabe que, desde o início da revolução industrial, a civilização ocidental esteve exposta a pandemias que se repetem a cada cem anos. Tivemos, assim, a epidemia de cólera, que causou centenas de milhares de mortes na Europa entre 1817 e 1824, a gripe espanhola, com vinte milhões de mortos (cifra de longe maior do que o número de vítimas das duas grandes guerras mundiais), nos anos de 1918 e 1919, e finalmente a pandemia do coronavírus, que até o momento em que respondo a essa entrevista nos deixa o mórbido rastro de aproximadamente 1900.000 mortes, das quais quase 200.000 já se contabilizam em nossos tristíssimos auriverdes trópicos. Mas, embora seja de se supor que a esses períodos se sigam padrões comportamentais de cautela social, o que se sabe, conforme testemunhado por Mário Filho, jornalista e irmão do dramaturgo Nélson Rodrigues, é que ao fim da gripe espanhola, em 1919, assistiu-se ao maior evento carnavalesco de que já se teve notícia no Rio de Janeiro, poucos meses após suas ruas se tornarem palco de cenas macabras, com cadáveres recolhidos nas calçadas por caminhões de lixo e enterrados em valas comuns. Não creio, por conseguinte, que teremos que nos haver com uma epidemia de padrões obsessivo-compulsivos de mal-estar, ao fim da pandemia, valendo inclusive lembrar que o que caracteriza essas formas neuróticas de comportamento é, justamente, a falha do teste de realidade que levaria o próprio sujeito a reconhecer o caráter descabido de suas reações. De todo modo espero, embora duvide profundamente de minha esperança, que após essa crise, a imagem de ônibus lotados, 
hospitais repletos e descaso pelos serviços de saúde pública nos escandalizem suficientemente para exigir maior empenho de nossos atores políticos na mudança dessas situações.

Mas o novo normal, que realmente me preocupa, na notificação da atual pandemia, é assistirmos à substituição da circulação das evidências factuais pela propagação desenfreada de notícias falsas pautadas nos interesses de grupos particulares. Tal como a Hidra de Lerna, da mitologia antiga, que ao se lhe cortar uma cabeça apareciam outras dez, a impressão que se tem é a de que essa circulação de falsas notícias hoje se dá com tamanha rapidez que, quando conseguimos debelar uma delas, vemos se multiplicar dez outras, ainda mais estapafúrdias que as primeiras. Assusta-me receber, até mesmo de colegas médicos, informações via WhatsApp sobre a eficácia da cloroquina e bobagens afins que não se apoiam em nenhum estudo minimamente controlado de sua indicação, em razão, eles dizem, de que se deve tentar qualquer coisa, quando eles mesmos sabem da inutilidade do que estão anunciando. $O$ novo normal é esse "mercado mundial da mentira" que Lacan já previra em seu discurso sobre $A$ coisa freudiana ${ }^{4}$, no ano de 1956, anunciando a guerra do século XXI que hoje se dispersa, como nota J.-C. Milner ${ }^{5}$, não mais a partir de QGs concentrados, mas em redes de desinformação dificilmente localizáveis que promovem, em nome ideologias execráveis, o aniquilamento de populações das quais nem mesmo se tem conhecimento.

TCS: Em que sentido a soberania do inútil, o sacrifício sem utilidade, pode redimir o laço social da onda de higienismo imperativo e intolerância contra todos os "inocentes do Leblon" e os da Rocinha, do Rio das Pedras e de outras comunidades cariocas que se recusam a aderir às novas normas sanitárias?

Não me parece acertada a proposta de transferir a ideia de "sacrifício sem utilidade" de Bataille $^{6}$ à promoção aberta de uma tolerância para com aqueles que se recusam a aderir às normas sanitárias de prevenção da COVID-19, nem tampouco nomear de higienismo imperativo contra os "inocentes do Leblon" a exortação pela adoção pública das regras de profilaxia comunitária. Existe, como disse no início, um fundamento ético, no meu entender, axiomático que diz respeito à proteção do direito de existir, o qual não pode e não deve de modo algum ser revogado em nome de um pretenso direito à liberdade que cada um tem do uso de seu próprio corpo, diante da evidência de que ter um corpo significa ser capaz de afetar outros corpos, e que o cuidado com os outros corpos não pode ser suprimido em nome de uma suposta liberdade de cada um fazer do próprio corpo o que bem entender. A ideia de "sacrifício sem utilidade", de Bataille, diz respeito a algo diverso: ela implica a recusa da submissão do corpo à função instrumental de coisa útil, numa esfera absolutamente distinta da reivindicação de gozo dos "inocentes do Leblon" que desprezam arrogantemente o fato de que o corpo, justamente por não se reduzir a uma vocação meramente instrumental, deve ser alvo de um cuidado desinteressado. 
TCS: A defesa intransigente de que "a economia não pode parar" por líderes como Boris Johnson, Trump e Bolsonaro (e por que não lembrar a decisão da Suécia de não fazer isolamento?) denota uma indiferença em relação à vida, uma necropolítica genocida, uma disposição nazista a repetir os horrores do holocausto?

É preciso tomar cuidado, como disse no início, em não tentar iluminar a obscuridade do presente com a luz crepuscular do passado, coisa que ocorre quando se busca conceber Trump e Bolsonaro como meras reedições de Hitler ou Mussolini. É certo que o nazismo contou, em seu início, com o apoio de representantes do liberalismo econômico, como foi o caso do exchanceler Von Pappen, que persuadiu Hindenburg a nomear Hitler como chanceler, garantindo que ele estaria sob seu controle, assim como é verdade que Giovanni Giolitti, político liberal eminente, transferiu sua credibilidade ao Partido Nacional Fascista de Mussolini. Qualquer semelhança com nosso atual Paulo Guedes talvez não seja mera coincidência. Mas, ainda assim, concordo com o que dizia A. Badiou, ao afirmar que de tanto procurar Hitlers por toda parte, esquecemos que ele está morto e que o mal assume singularidades inéditas. Mas se existe algo de interessante que essa pandemia trouxe à luz é, justamente, a possibilidade de se tentar fazer a economia, senão parar, pelo menos reduzir essa aceleração insana que hoje nos conduz a uma catástrofe ambiental já sem retorno, da qual podemos no máximo mitigar os efeitos.

Rachel Amin gostaria de esclarecer alguns pontos levantados em A Ciência e a Verdade, na Conferência de Genebra, em Falo com as paredes e Salvação pelos dejetos (textos mencionados por Fabian Fanjwats ${ }^{7}$ na Live que Antônio Teixeira promoveu juntamente com 0 Labtrans $^{8}$ de 01/08/2020)

Rachel Amin: Em A Ciência e a verdade9, Lacan diz que é necessário introduzir na consideração científica o Nome-do-Pai. Na Conferência de Genebra ${ }^{10}$ afirma que o importante para a sustentação do simbólico e do real, seria que alguém consentisse em encarnar a função de autoridade. O declínio dos lugares de autoridade estaria promovendo sujeitos descrentes. Você dedicou um artigo às Fake News ${ }^{11}$. Qual a relação entre o declínio dos lugares de autoridade, a promoção de sujeitos descrentes e a proliferação de fake news?

De fato, se percebe, na própria constituição do saber científico, em sua fundação cartesiana, uma exclusão radical da autoridade paterna, materializada na dúvida hiperbólica como uma atitude de revogação de todo saber homologado pela tradição. A recusa, por parte de Rousseau ${ }^{12}$, de toda autoridade em posição de exceção, em sua formulação do Contrato Social, assim como a definição dada posteriormente por Kant ${ }^{13}$ ao Iluminismo, como atitude de maioridade intelectual - na qual o sujeito deve aceder à verdade por meio de seu próprio saber -, renova em campos diversos a mesma concepção de uma subjetividade que se quer 
autônoma. Se essa proposta moderna de autonomia comporta, no dizer de Lacan, "algo que merece em todos os pontos ser comparado a um discurso delirante" ${ }^{14}$, isso se verifica, em seus efeitos, por um movimento de identificação massiva do sujeito ao mundo progressivamente percebido como expressão de sua vontade em conformidade com as leis algébricas determinadas por sua natureza pensante. Nada mais existe por si: as montanhas de Minas Gerais se reduzem a complexos calculáveis de extração de minério de ferro, assim como as cataratas de Sete Quedas, sobre as quais o poeta Carlos Drummond de Andrade ${ }^{15}$ teceu um belíssimo necrológio, tiveram que desaparecer para dar lugar a um dispositivo de produção de kilowatts. Não é, aliás, casual que no universo mecânico engendrado pela ciência, o próprio sujeito passe a ser concebido segundo o modelo de uma máquina pensante. Mas seja qual for o alcance dessa antropologia mecanicista, o fato é que em nossa visão do mundo, naturalizada pelo discurso da ciência, as coisas só chegam à consideração do Ser, como salienta Jacques-Alain Miller ${ }^{16}$, em função de sua utilidade calculável. Acredito, nesse sentido, que a necessidade, indicada por Lacan (1965-66), de introduzir no discurso da ciência a consideração do Nome-do-Pai responde, de certa forma, à urgência de resgatar um princípio de percepção do mundo que não seja anônimo, que não se reduza a um cálculo abstrato.

Parece-me, por outro lado, um pouco duvidosa essa famosa tese do declínio da autoridade paterna, assim como a ideia de que alguém deva consentir a encarnar essa autoridade, proposta que, aliás, não se encontra assim formulada em sua Conferência de Genebra (Lacan, 1975) sobre o sintoma. De fato, a famosa tese do declínio da autoridade paterna se encontra em alguns aspectos apoiada na leitura de Durkheim pelo jovem Lacan dos Complexos Familiares de 1938, que se refere ao fenômeno moderno de contração do antigo patriarca ao pai reduzido ao talo da família conjugal. Não obstante sabemos, conforme nos indica M. Zafiropoulos ${ }^{17}$, que estudos historiográficos conduzidos pela Escola de Cambridge, nos anos 70, demonstraram que a forma conjugal de família não é um fenômeno exclusivamente moderno. Ela remonta ao século XVI, valendo lembrar que mesmo na Roma antiga, à qual os

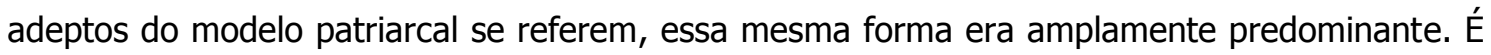
interessante notar, segundo ainda Zafiropoulos, que o Lacan do retorno a Freud, de 1951, é um Lacan que se distancia de Durkheim, no mesmo momento em que se deixa influenciar pela vertente estruturalista de Jakobson e Lévi-Strauss, que the permite pensar de maneira radicalmente distinta a função do pai como exceção. A Lacan não escapa o dado enfatizado por Lévi-Strauss, relativo ao lugar ocupado pelo significante mana das tribos polinésias, isolado por Marcel Mauss, em seu ensaio sobre o dom. 0 que permite a esse significante ocupar um lugar de exceção, na ordenação da linguagem, é o fato dele não se ligar a nenhuma significação eminente, mas antes se encontrar esvaziado de todo conteúdo significativo. Sua potência reside não em sua plenitude, mas em seu esvaziamento de símbolo no seu grau zero. Nesse sentido, se o Lacan do retorno a Freud é um Lacan marcado pelo estruturalismo, ele o é, dentre outros 
aspectos, na medida em que o dispositivo estruturalista lhe permitiu se emancipar da formulação falaciosa relativa à potência imaginária do patriarca de E. Durkheim. Foi por se armar da leitura de Lévi-Strauss do significante mana que Lacan pôde formular a tese, fundamentalmente freudiana, que coloca a função de exceção no nível do vazio simbólico referido ao pai morto, como um significante cuja eficácia deriva de seu esvaziamento de todo conteúdo significativo. A exceção, para efetivamente funcionar, deve poder se apagar, como já havia intuído, na Grécia Antiga, o legislador Sólon que ao ser convocado a remediar uma situação de conflito, sai da cidade logo após instaurar a decisão reguladora.

Esse dado me parece particularmente importante para responder a sua pergunta, quando você fala de sujeitos descrentes, justamente pelo fato de que somente ao Pai, enquanto suporte vazio de um Nome, se pode dirigir uma crença, ao passo que o pai, em sua pura individualidade empírica, apenas gera rivalidade ou descrença. Interessante notar, a esse respeito, que o que confere poder ao líder totalitário decorre muito mais de fenômeno de emulação imaginária do que de uma atitude de verdadeira reverência. Eu concordo com o que formula Vladimir Safatle ${ }^{18}$, em relação a esse ponto, quando ele diz que o fascismo, longe de ser uma expressão da autoridade paterna, antes corresponde à sua falência na forma de uma caricatura que reproduz, para o sujeito, a sua indigência individual, ao conferir poder como autorização à violência nascida do ressentimento de sua subjetividade miserável. Dali provém o comportamento grotesco de quem se diz se identificar ao "homem do povo" ao proferir obscenidades em reunião ministerial, ou anedotas infames, em lives dirigidos a seus prosélitos, em meio a injúrias homofóbicas, elogios a práticas de extermínio, insultos racistas e ameaças renovadas às instituições democráticas. Nesse sentido, a proliferação das fake news, tanto para o serviço de propaganda política de Goebbels ${ }^{19}$ quanto para o atual gabinete do ódio ${ }^{20}$, responde à mesma vontade de compor essa localização do inimigo, e assim construir uma identificação que se sustenta na possibilidade de revidar sobre aquele que dela não faz parte suas frustrações imaginárias.

RA: Temos hoje o mundo dividido entre aqueles que consideram o real e os que não. Você acredita que, de forma geral, há uma consideração pelo real, ou as informações e posições desencontradas entre os cientistas estão promovendo um aumento da descrença $e$ consequente desconsideração da gravidade da situação atual? Diante de qual mestre estaríamos expostos na atualidade e quais os efeitos deste mestre na politização da saúde, na biopolítica e no mercado?

Gosto de manter a ideia lacaniana do real como aquilo que não recebeu tratamento simbólico, e que nesse sentido se manifesta fora de uma articulação discursiva. Dessa ideia emergem duas possibilidades. A primeira diz respeito ao retorno catastrófico do real quando se visa a uma totalização sem restos da realidade pelo simbólico, a qual podemos ilustrar, entre 
inúmeros exemplos, nos fenômenos de desequilíbrio planetário gerados pela articulação do capitalismo com a ciência nesse período que hoje chamamos de antropoceno. A outra ideia, para a qual nos conduz a experiência psicanalítica, é a de que se deve abrir espaço, no campo da realidade psíquica, para algo que nela não se articula, mas que mesmo assim merece admissão. É o momento, por exemplo, em que mostramos ao paciente que aspectos determinantes de sua narrativa do mundo se encontram estruturalmente excluídos dos efeitos de sentido que essa mesma narrativa permite, e convidamo-lo a aceitá-los em sua essencial contingência. $O$ interessante hoje é pensar que existe um retorno catastrófico do real relativo ao risco de nossa sobrevivência no ambiente que tanto degradamos, o qual se manifesta de maneira evidente para o discurso da ciência, que é o único discurso capaz de realmente antecipá-lo, através de cálculos matemáticos precisos. O problema é que a ciência, essa Cassandra ${ }^{21}$ contemporânea, não dispõe de uma narrativa que permite evitar o risco por ela previsto, uma vez que as questões éticas envolvidas na construção dessa evitação, tais como o valor da vida ou sua harmonia ecológica, são estruturalmente revogadas pelo discurso científico. Só há ciência, já dizia Rabelais, citado por Lacan, daquilo que não tem alma nem consciência. A ciência prevê o desastre, o cientista tenta avisar aos demais, mas não dispõe de uma narrativa que permita evitar sua fatalidade. Nesse sentido, ao construir uma visão mecanicista da natureza, colocada a serviço de cálculo de sua extração, a ciência se viu refém do discurso do capitalismo que the deu meios financeiros para se desenvolver, desde que ela se mantivesse indiferente aos problemas que seus representantes já não mais conseguem calar. Mas eles não conseguem calar o discurso do capitalismo, pois a necessidade de se manter a exploração infinita é inerente a esse sistema, que dela depende para sobreviver. O capitalismo é um sistema sem ponto de basta, uma vez que ele vive justamente do que Lacan chama de circulação infinita do mais-gozar, convertendo-o numa promessa que deve habitar cada indivíduo que esse discurso determina. $\mathrm{E}$ isso atinge tanto as piores quanto as "melhores" pessoas. Se por um lado temos o negacionismo criminoso de um Trump ou de um Bolsonaro, que mentem descaradamente sobre a natureza do problema que Ihes é comunicado, temos, por outro lado, um conjunto de bons velhinhos aposentados da Europa que escolhe para gerir seu fundo de pensão a empresa de consultoria que oferece a maior rentabilidade a menor custo. Ao adquirir ações da Vale, no Brasil, essas pessoas bem intencionadas não buscam se informar se o aumento de rentabilidade de seu fundo de pensão se encontra ligado à ausência de políticas ambientais cujo custo diminuiria o lucro dessa empresa. Eles se consternam um pouquinho ao assistir a reportagem televisiva sobre os terríveis desastres de Mariana e Brumadinho, no intervalo entre a previsão do tempo, o programa esportivo e o show de variedades, sem que isso perturbe realmente o seu sono. Pois é assim que funciona, isso se encontra naturalizado. O mais assustador é que quando os cientistas não conseguem mais compactuar silenciosamente com isso, o discurso do capitalismo prefere revogar a própria 
pertinência do discurso da ciência, afogando a mínima possibilidade de senso crítico comunitário que esse discurso permite no oceano de falsa ciência que hoje circula nas redes sociais.

RA: Em tempo da multiplicidade e declínio do Nome-do-pai, da foraclusão da castração e da elevação ao zênite (não mais do objeto a como Miller ${ }^{22}$ sugeria em Comandatuba) mas, do sem sentido elevado à máxima potência com a pandemia, você acredita que isso vai repercutir no campo da ciência? E quais as consequências da polarização entre a supremacia das ciências da gestão e as críticas ao neoliberalismo nas ciências humanas? Fabian ${ }^{23}$ faz uma alusão à possibilidade da psicanálise ganhar aí uma maior via de ação. O que você acha disso?

Certamente que tudo isso repercute no campo da ciência, sobretudo quando ela mesma vê se dissipar sua autoridade e se encontra obrigada a se adaptar a essa situação para sobreviver. Diante do imperativo de circular notícias que hoje valem mais por sua capacidade de excitar afetos e likes do que pela missão de informar, os próprios cientistas, eles mesmos submetidos à exigência de publicar para não perecer (publish or perish), assistem desoladamente à conversão do produto de seu saber em sua forma-mercadoria. Sabemos, também, no que tange à própria universidade enquanto instituição vocacionada, em sua fundação clerical, a converter ao saber universal o que se apresentava no circunstancialmente como saber originalmente múltiplo, que ela encontrou no discurso da ciência o seu lugar de eleição por ali dispor de um saber formal, depurado de todo conteúdo particularizado. Mas, na medida em que dissipa a crença nesse saber calculante da ciência, o Um para o qual a Universidade uni-versa, se vocês me permitem transformar o substantivo em verbo, reduz-se hoje, conforme indica J.-C. Milner ${ }^{24}$, ao Um da forma-mercadoria. Isso se dá porque existe, para além da unidade formal do cálculo científico, outro modo de unidade indiferente ao conteúdo que Marx ${ }^{25}$ situa com o conceito de forma de equivalência geral. Se, do ponto de vista do valor de uso, os objetos podem variar qualitativamente, ao abstrairmos o seu valor de uso para entrar na perspectiva do valor de troca, as qualidades particulares desses mesmos objetos se apagam para se tornarem relações comparativas de valores abstratos. Assim como o cálculo sobre a massa e aceleração se aplica a qualquer objeto no campo da física, independente da particularidade de sua apreensão individual, o dinheiro como forma de equivalência geral, ao funcionar como meio de permutabilidade direta entre os objetos convertidos à formamercadoria, no universo mercantil, se define como um valor abstrato que pode ser aplicado indiferentemente a qualquer objeto de troca. Dali se deduz a importância dessa transformação ideológica na constituição da massa universitária: diante da propagação dos pontos de vista particulares no campo ilimitado dos saberes múltiplos, onde não se pode mais ser indiferente ao conteúdo de cada doutrina, a ideologia mercantil permite restabelecer a perspectiva do Universal, no nível da própria consideração dos saberes circulantes, por meio da apreensão 
puramente contábil do saber-mercadoria em sua forma de equivalência geral, independente do seu teor ou da natureza de seu objeto.

Por isso notamos que o mestre universitário contemporâneo hoje se tornou, tal como um produto do mercado, uma peça removível, inteiramente substituível por outra. Seu ensino se autoriza menos por sua enunciação do que por sua inscrição na engrenagem universitária em que deve funcionar. $E$ do mesmo modo que ao capitalista interessa menos a razão de ser, a qualidade particular ou a essência do objeto transformado em mercadoria, do que a medida da quantidade, do custo e da margem de lucro relativa ao produto desse modo constituído, no caso da produção universitária, submetida à lógica desse discurso, importa menos a natureza do saber que ela produz, do que a medida de equivalência que permite tratar o saber como artigo a ser ofertado no mercado.

Dali se explica, conforme já pude comentar em outros momentos, a expansão desenfreada das práticas de avaliação, no ensino universitário, calcada na exigência de se criar um sistema de equivalência geral destinado à padronização e à quantificação do saber enquanto produto comercializável. Pois o que está efetivamente em questão, nessa transformação do saber em mercadoria, diz respeito à exigência de uma forma de equivalência geral própria ao regime do contrato no contexto mercadológico, o qual permite ao adquirente de um produto verificar se aquilo que ele obteve corresponde ao que ele de fato queria ter obtido na formulação de sua demanda. A relação contratual assim supõe, em sentido contrário à condição que sustenta o desejo, a correspondência entre demanda e satisfação; a esse fim se destinam, conforme já nos indicavam Miller $\& M_{i l n e r^{26}}$, as infindáveis cláusulas contratais. Para se assegurar de que o sujeito saiba do que está falando, é preciso suturá-lo no nível de uma demanda codificada de uma linguagem isenta de equívocos. O problema, todavia, do ponto de vista do ensino universitário no campo da assim chamada saúde mental, é que não existe padronização do sofrimento psíquico. Por mais que se criem protocolos de coaching ou de readaptação funcional, não há como exigir do sujeito que sofre de seus pensamentos que ele saiba de antemão do que está falando, a fim de lhe ofertar o produto demandado na forma mercadoria de um dispositivo terapêutico. Dar a palavra ao paciente requer, pelo contrário, como demonstra a clínica psicanalítica, a suspensão de toda codificação da demanda relativa ao sofrimento psíquico.

O problema é que o mestrezinho contemporâneo, projetado na figura tão enfatuada quanto servil do gestor, necessita preencher sua planilha com dados estatísticos obtidos a partir da reprodução do caso tipificável. Diante da dificuldade de se definir, por meio de uma doutrina de saber, no campo da saúde mental, o caso reprodutível destinado à avaliação padronizável, resta-Ihe propor, ainda que envergonhadamente, uma codificação arbitrária. Por isso a nosologia que veio em socorro ao gestor, iniciada pelo DSM e finalmente adotada pelo CID, apoia-se numa tipologia de convenções discricionárias dissociada de todo esforço de teorização. 
O que assim explica a lassidão bocejante que afeta o aluno obrigado a estudar as divisões classificatórias dos atuais compêndios de psiquiatria, cujas listagens agrupam fenômenos sem conexão entre si, é o abandono deliberado de todo esforço de se situar, logicamente, o sintoma como resposta do ser falante ao mal estar que o aflige. Interessa somente reter o que se deixa codificar numa forma de equivalência geral, segundo os parâmetros de uma prática que deve se submeter a avaliações de produtividade para prestar contas aos poderes que a subvencionam. A epistemofobia é, nesse sentido, o corolário inevitável da epistemometria. Por esse motivo há interesse em notar, como você observa no final de sua pergunta, que a psicanálise, tão avessa à atual prática de avaliação, continue a suscitar uma adesão entusiástica dos estudantes e pesquisadores ainda não inteiramente bestificados pela epistemometria. Acreditamos que o que assegura a transmissão da psicanálise nas universidades, gerando um movimento de entusiasmo independente do seu reconhecimento contábil pelos poderes avaliadores, diz respeito a sua capacidade de resgatar uma epistemofilia, de suscitar, pela via do amor transferencial, o desejo pelo saber que se perdeu nos relatos clínicos da psiquiatria atual.

RA: Você acha que há uma relação entre a diminuição do consumo e a intensificação da ambivalência no laço social? Se a psicanálise nos oferece a ferramenta não apenas de leitura da época, mas também de intervenção na lógica vigente, como você sugere que os analistas sustentem a dimensão do real através de sua leitura crítica do contexto atual?

De fato, a saída pelo consumo, na forma compulsiva que o discurso do capitalismo promove, permite ao sujeito se haver com a satisfação sem ter que passar pelo consentimento do Outro. Pois se haver com o consentimento do Outro implica se transformar ao transformar a ficção que dá existência ao Outro, implica seduzir o Outro e se deixar encantar por ele, escutar e se fazer ouvir, implica enfim aceitar a impossibilidade de fazer corresponder projetivamente a demanda e a representação social de seu objeto. A saída cínica, que permite se eximir do Outro, não é apanágio somente das toxicomanias. Ela se dá tanto na compulsão por compras quanto na bulimia, tanto no consumo desenfreado da pornografia quanto na busca de excitações codificadas pelos ambientes de rede social. A diminuição da disponibilidade de consumo desencadeada pela pandemia pode, nesse sentido, talvez não intensificar, mas desanestesiar o ser falante de parcerias vividas em regime de solidão coletiva, ao diminuir a possibilidade de curto-circuito de uma satisfação pulsional que até então permitia tolerar a presença de outra pessoa dela se ausentando. Interessante notar que, assim como a insônia se agrava com a imposição de ter que dormir, a saída compulsiva se alimenta estruturalmente de sua própria interdição. Quanto mais o sujeito tenta impedi-la, mais ela se intensifica. A eficácia que o psicanalista pode ter, em relação à saída compulsiva, depende dele não se opor a ela para deixar que ela se esvazie até seu nível residual mínimo, que varia para cada pessoa. Ao 
suportar ser a causa do desejo, sem se converter em objeto de satisfação, o analista pode dar ao sujeito a possibilidade de fazer do Outro um lugar habitável, na forma de uma promessa que não se dissipa no curto-circuito da solução compulsiva.

Jaqueline Ferreira: A sociedade contemporânea permanece atrelada à norma, ao saber, à vida, ao sentido, às disciplinas e às regulamentações tais como foram explicitadas por Foucault e a pandemia da covid-19, reforçaria ainda mais os "biopoderes" ${ }^{28}$ sobre a vida e a "biopolítica"?

De fato, quando Foucault ${ }^{28}$ se referia ao biopoder, em sua constituição a partir do século XIX, ele se ocupava de entender uma transformação que dizia respeito à exigência de controle, pelo Estado, sobre o homem enquanto vida socialmente investida. É nesse sentido que o assim chamado darwinismo social tornou-se uma maneira de transcrever, em termos biológicos, a narrativa do discurso político, autorizando medidas de sanitarismo que iam desde o controle dos corpos às práticas de eugenia apoiadas nas teorias de degenerescência em voga até a primeira metade do século XX. Importa, todavia, notar que não foram as pandemias, que como sabemos se repetem regularmente na história, que suscitaram tais práticas de controle disciplinar, mas sim a grade de leitura que tal política passou a dar a esses fenômenos. Se pensarmos na história do termo pandemia, empregado pela primeira vez, em 1666, pelo médico Gideon Harvey, em seu estudo sobre a tuberculose, constatamos que ele permanece uma noção de uso vago e impreciso para entrar no dicionário somente em 1824, no momento, portanto, em que a grade discursiva constituída por uma biopolítica nascente oferecia a esse fenômeno seu lugar de destaque.

Nesse sentido, podemos efetivamente falar da atual pandemia como um pretexto para o reforçamento do discurso a que deu relevância, mas lembrando que tal discurso ganha contornos distintos daqueles descritos por Foucault. A biopolítica em nosso tempo parece preferencialmente se apoiar naquilo que o filósofo italiano Roberto Esposito chama de paradigma imunitário, pelo qual se demonstra a relação orgânica entre os conceitos de comunidade e imunidade. A ideia, para resumi-la brevemente, é a de que haveria um ônus a ser pago por todo aquele que se integra a uma comunidade, cuja contrapartida seria a imunização como possibilidade de se dispensar desse tributo, ao dispor de um direito que não se partilha como bem comum. É o que se dá quando o filho de um certo presidente se vale, por exemplo, de sua imunidade parlamentar para não se submeter ao ônus de prestar contas de determinado ganho flagrantemente indevido. De forma que se, por um lado, a comunidade determina uma participação contributiva como condição de pertencimento, pela imunidade o sujeito se coloca na via de uma recusa defensiva dessa participação. Nesse sentido, percebemos que quando um grupo de pessoas se declara imune à infecção pelo Covid 19, se negando a colaborar com o gesto que impede a sua propagação, ele o faz expondo aqueles 
declarados não imunes como sujeitos a pagar de sua própria vida os efeitos catastróficos dessa recusa de compartilhamento.

JF: Canguilhem afirmou certa vez: "[...] A doença não é somente desequilibrio ou desarmonia; ela é também, e talvez, sobretudo, o esforço que a natureza exerce no homem para obter um novo equilíbrio. $A$ doença é uma reação generalizada com intenção de cura. $O$ organismo desenvolve uma doença para se curar $[. . .]^{\prime 22}$. Esse raciocínio se aplica à pandemia?

De fato, Canguilhem renova uma noção já formulada por Locke, filósofo médico que já nos exortava, no século XVII, a observar o adoecimento como uma tentativa de cura, assim como Freud percebia no delírio um esforço de reconstrução da realidade pelo sujeito na psicose. Se pensarmos, por outro lado, nos termos de uma macro-história, seja ela biológica ou humana, podemos também aceitar a ideia de que nossa estrutura vital igualmente dependeu, para se constituir, de soluções condicionadas por modificações genéticas induzidas por replicações virais ao longo dessa transformação multimilenar a que damos o nome equivocado de evolução. 0 médico infectologista Stefan Ujvari ${ }^{30}$ nos mostra, em $A$ história da humanidade contada pelos vírus, como os recentes estudos de mutação genética nos permitem reconstituir as transformações de nosso próprio modo de estar no mundo através dos rastreamentos dos efeitos produzidos pelas infecções virais. Ao incorporarem seus genes nas células invadidas, 0 vírus concorre para acelerar seleções aleatórias que suprimem ou otimizam a permanência de características que podem alterar o próprio comportamento social de nossa espécie.

Mas se tomarmos a questão do ponto de vista da micro-história recente, temos motivos para crer que, assim que essa última pandemia seja controlada para se tornar um problema endêmico crônico, o mundo deve voltar a girar como antes. Existe algo no nosso próprio modo de ver o problema que faz com que voltemos à estaca anterior. Se você perguntar, a título de ilustração, a um aluno de medicina pela causa da tuberculose, ele irá de imediato responder que é o bacilo de Koch, mas são raros os que se dispõem a situar essa causalidade nas condições de insalubridade do trabalhador inglês no século XVIII, por exemplo. Analogamente, ao tomarmos, como se faz hoje, o coronavírus como agente etiológico e foco de controle desse fenômeno pandêmico, deixamos intocadas causalidades outras que o sistema atual de organização social não quer modificar, como os modos absolutamente cruéis de criação intensiva e processamento de animais para produção e distribuição de proteína, assim como as altíssimas taxas de concentração populacional e pobreza, além de uma lista de outros problemas que não conseguiria repertoriar aqui. Mas seja como for, modificar a estrutura social que condiciona esses problemas requer um trabalho paciente que não rende dividendos políticos, por isso nos concentramos em atacar somente o vírus para voltarmos a funcionar como antes. 
Agradecemos a grande generosidade do colega Antônio Teixeira que, com paciência, erudição e forte determinação epistêmica compartilhou conosco reflexões profundas e despertou ou renovou no espírito de nossos leitores a vontade de visitar autores clássicos da literatura filosófica e psicanalítica.

\section{Notas do revisor:}

1. Teixeira, A. (2009). A soberania do inútil. E outros ensaios de psicanálise e cultura. SP: Annablume.

2. Agamben, G. (2009). O que é o contemporâneo? E outros ensaios. Chapecó. SC: Argos, p. $65 . \quad$ Recuperado de <https://edisciplinas.usp.br/pluginfile.php/4332647/mod resource/content/3/contempa gamben.pdf $>$.

3. Agambem, G. (2020, fevereiro 20). O estado de exceção provocado por uma emergência imotivada. Recuperado de <http://www.ihu.unisinos.br/78noticias/596584-o-estado-de-excecao-provocado-por-uma-emergencia-imotivada $>$.

4. Lacan, J. (1998). A coisa freudiana ou Sentido do retorno a Freud em psicanálise. In J. Lacan. Escritos. (pp. 402-437). Rio de Janeiro: Jorge Zahar Editor. (Trabalho originalmente publicado em 1956)

5. Milner, J-C. (2014). L'Universel en éclats. Paris : Verdier, p. 20.

6. Bataille, G. (1971). O Erotismo (Tradução de Antônio Carlos Viana). Porto Alegre: L\&PM Editores.

7. Encontro 1 - Sem fins lucrativos: o lugar das humanidades no contexto atual LABTRANS UFMG. Recuperado de $<$ https://www.youtube.com/watch?v=KdCTAutEkoY>.

8. LABTRANS UFMG - Laboratório Transdisciplinar: família, parentalidade e parcerias sintomáticas: <https://labtransufmg.wordpress.com/>.

9. Lacan, J. (1998). A ciência e a verdade. Escritos (pp.869-892). Rio de Janeiro: Jorge Zahar Editor. (Trabalho orginalmente publicado em 1965-1966)

10. Lacan, J. (1998). Conferência de Genebra sobre o sintoma. Opção Lacaniana Revista Brasileira Internacional de Psicanálise (23), 6-16. São Paulo: Edições Eólia. (Trabalho original publicado em 1975).

11. Teixeira, A. M. R. (2019). Lost in Fake News. Coelho dos Santos, T.; Santiago, A. L.; Garcia de Oliveira, F. L. (Orgs.). Reconfigurações do imaginário no século XXI. (pp. 3346). Curitiba (PR): Ed. CRV.

12. Rousseau, J.-J. (2013). Do contrato social: princípios do direito político (Tradução de Vicente Sabino Júnior). São Paulo: Ed. Pilares. 
13. Kant, I. (1995). Resposta à pergunta o que é Iluminismo. Kant, Immanuel. $A$ Paz Perpétua e outros Opúsculos. São Paulo: Edições 70.

14. Lacan, J. (1998). A ciência e a verdade. Escritos (pp.869-892). Rio de Janeiro: Jorge Zahar Editor. (Trabalho orginalmente publicado em 1965-1966)

15. Drummond de Andrade, C. (1982). Adeus a Sete Quedas. Jornal do Brasil, Caderno B, 09/09/1982.

16. Miller, J.-A. (1993, setembro). Le despotisme de l'utile. La machine panoptique de Jeremy Bentham, Barca!, n 1, p. 154.

17. Zafiropoulos, M. (2002). Lacan y las ciencias sociales: La declinación del padre (19381953). Buenos Aires: Ediciones Nueva Visión, pp. 27-58.

18. Safatle, V. (2008). Cinismo e falência da crítica. São Paulo: Boitempo.

19. Paul Joseph Goebbels (1897-1945) - político alemão e Ministro da Propaganda na Alemanha Nazista entre 1933 e 1945. Um associado e devoto apoiante de Adolf Hitler, ficou conhecido pelas suas capacidade de oratória em público e pelo seu profundo e fanático antissemitismo, e sua crença na conspiração internacional judaica que o levou a apoiar o extermínio dos judeus no Holocausto (ref. Wikipedia).

20. "Gabinete do ódio é como internamente integrantes do governo passaram a se referir ao grupo formado por três servidores ligados ao vereador do Rio de Janeiro Carlos Bolsonaro (PSC), filho "02" do presidente. Os assessores Tércio Arnaud Tomaz, José Matheus Sales Gomes e Mateus Matos Diniz produzem relatórios diários, com suas interpretações, sobre fatos do Brasil e do mundo, e são responsáveis pelas redes sociais da Presidência da República". Recuperado de $<$ https://www.gazetadopovo.com.br/republica/gabinete-do-odio-alvo-cpmi-fakenews/>.

21. Ref. "Cassandra Cain (também conhecida como Cassandra Wayne) é um super-herói fictício que aparece nos quadrinhos americanos publicados pela DC Comics, comumente em associação com o super-herói Batman. [...] A história de origem de Cassandra a apresenta como a filha dos assassinos David Cain e Lady Shiva. Ela foi privada da fala e do contato humano durante sua infância como condicionamento para se tornar a maior assassina do mundo. Consequentemente, Cassandra cresceu para se tornar uma especialista em artes marciais e desenvolveu uma incrível habilidade de interpretar a linguagem corporal ao ponto de ler pensamentos complexos, mas ao mesmo tempo permanecendo muda, desenvolvendo habilidades sociais muito limitadas e sendo analfabeta. Cassandra foi a primeira Batgirl a estrelar sua própria série de quadrinhos Batgirl [...]". (Wikipédia).

22. Miller, J.-A. (2004). Uma fantasia. Conferência feita em Comandatuba (BA) durante o IV Congresso da Associação Mundial de Psicanálise. Recuperado de 
$<$ http://2012.congresoamp.com/pt/template.php?file=Textos/Conferencia-de-JacquesAlain-Miller-en-Comandatuba.html>.

23. Idem nota 7.

24. Milner, J.-C. (2014). De I'Université comme foule. In L'Universel en éclats, Paris, Verdier, 2014, pp. 87-114.

25. Marx, K. (1983 [1867]). O capital: crítica da economia política. Livros I, II e II. São Paulo: Boitempo, 2011, 2014, 2015.

26. Miller, J.-A., \& Milner, J.-C. (2006). Você quer mesmo ser avaliado? Barueri (SP): Manole.

27. Biopoder - "Foucault usou-o em seus cursos no Collège de France, mas ele apareceu pela primeira vez em $A$ vontade de saber, primeiro volume da História da Sexualidade." (Wikipedia).

28. Canguilhem, G. (2006). O normal e o patológico. Rio de Janeiro: Forense Universitária, p. 10.

29. Ujvari, S. C. (2008). A história da humanidade contada pelos vírus. São Paulo: Ed. Contexto.

Citação/Citation: Coelho dos Santos, T., Amin, R., Ferreira, J. (mai. 2020 a out. 2020). Entrevista com o psicanalista Antônio Teixeira. Revista aSEPHallus de Orientação Lacaniana, 15(30), 139-155. Disponível em www.isepol.com/asephallus. Doi: 10.17852/1809-709x.2020v15n30p139-155

Editor do artigo: Tania Coelho dos Santos.

Recebido/Received: 04/03/2020 / 03/04/2020.

Aceito/Accepted: 04/20/2020 / 20/04/2020.

Copyright: (c) 2019 Associação Núcleo Sephora de Pesquisa sobre o moderno e o contemporâneo. Este é um artigo de livre acesso, que permite uso irrestrito, distribuição e reprodução em qualquer meio, desde que o autor e a fonte sejam citados/This is an open-access article, which permites unrestricted use, distribution, and reproduction in any medium, provided the author and source are credited. 